\title{
MORPHOMETRY OF DRY SUB AXIAL VERTEBRA: A NEPALESE STUDY
}

\author{
Dhakal A, ${ }^{1}$ Adhikari $P^{2}$ Ranjit $N,{ }^{3}$ Budhathoki $D^{4}$
}

${ }^{1}$ Department of Anatomy, Birat Medical College, Tankisinwari, Biratnagar, ${ }^{2}$ Department of Orthopedics and Trauma, HAMS hospital, Dhumbarahi, ${ }^{3}$ Department of Anatomy, Maharajgunj Medical Campus, Maharajgunj, Kathmandu, ${ }^{4}$ Department of Anatomy, Kathmandu Medical College, Sinamangal, Kathmandu, Nepal

\begin{abstract}
There is paucity in literature describing the morphology of sub-axial vertebra of the local population. Available studies are limited to the body, intervertebral disk, spinal canal and Torg's ratio of the cervical vertebra. Therefore, the present study aims to document various morphological parameters of sub axial vertebra. Sixty-four dry sub-axial vertebrae of the Nepalese population were studied using Vernier Calipers calibrated to $0.1 \mathrm{~mm}$ accuracy. Paired parameters of pedicle, lamina, uncinate process, the distance of the apex of the uncinate process to intervertebral foramen and foramen transversarium were measured. Similarly, unpaired parameters including spinous process length, vertebral foramen anteroposterior width, vertebral foramen transverse diameter and Torg's ratio were evaluated. Except the height of left lamina of C3 to C6 vertebrae, none of the parameters showed significant side differences. Significant higher values of C7 were noted against C3-C6 on vertebral body height, vertebral body anteroposterior diameter, spinous process length and vertebral foramen anteroposterior diameter. Population data of sub-axial vertebra available in literature showed mixed results with ours. Interestingly, our observations either compared to (lamina, uncinate process, anteroposterior diameter of spinal canal and Torg's ratio) or were larger (Pedicle and spinous process) than the Indian study with pedicle axis length being largest among all the compared studies. The information of this study may be used as a reference database for our local setting and could be of value in preoperative planning and in designing implants.
\end{abstract}

\section{KEYWORDS}

Cervical vertebra, lamina, Nepalese population, pedicle, uncinate process,

\section{CORRESPONDING AUTHOR}

Dr. Arun Dhakal,

Assistant Professor,

Department of Anatomy, Birat Medical College,

Tankisinwari, Biratnagar, Nepal

Email: arund@mail.ru,

Orcid No: https://orcid.org/0000-0002-2016-5713

DOI: https://www.doi.org/10.3126/nmcj.v23i1.36228 


\section{INTRODUCTION}

Seven cervical vertebrae constitute the skeleton of the neck. Each vertebra consists of vertebral body, pedicle, lamina, transverse process, spinous process, and superior and inferior articular process. ${ }^{1}$ Typical feature of these vertebrae is the presence of foramen transversarium in each transverse process and a notched spinous process. The third to sixth cervical vertebrae are typical possessing similar features whereas, first and second are atypical having specific features for their recognition. ${ }^{2}$ The seventh cervical vertebra is intermediary due to inconsistency in the presence of foramen transversarium. Various studies have documented the dimensions of the cervical vertebra. ${ }^{3-5}$ Also, racial factor seems to influence its morphometry. ${ }^{6-9}$

The cervical vertebra morphology and its regional anatomic relations, especially to the vertebral artery, veins, cervical medulla and the nerves are of crucial surgical importance. Various remedies have been devised to conserve the structure and function of the vertebra, for the ailments occurring as simple neck pain and dizziness to structural degeneration, compression and traumatic injury of this vertebra. ${ }^{5,7}$ Procedures like arthrodesis involving anterior cervical plate fixation or posterior lateral mass screw fixation for stabilization and its improved version, the transpedicular screw fixation has emerged as surgical intervention. ${ }^{3}$ Comprehensive knowledge about the size of vertebral elements is crucial, particularly for those processes requiring instrumentation associated with cervical spine, their treatment as well as advancement of implants. ${ }^{4}$ Though large number of studies on cervical morphology is available in the literature, it has been noted that there are only a few articles dedicated to the study in the Nepalese population. ${ }^{10-}$ ${ }^{12}$ Furthermore, the range of study of these articles regarding determining its morphology is limited. Therefore, the present study was carried to determine the morphology of dry sub axial cervical vertebra of the regional population.

\section{MATERIALS AND METHODS}

The local Institutional Review Committee (IRC), Birat Medical College and Teaching Hospital, Kathmandu University, Nepal, approved the study protocol. This study was carried out on 64 dry human sub axial cervical vertebrae of unknown age and sex obtained from Department of anatomy of Birat Medical college and

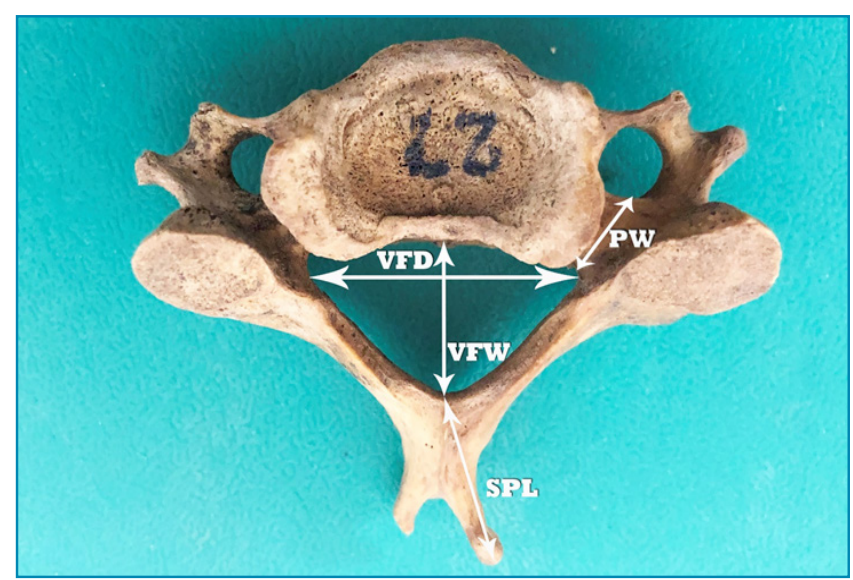

Fig. 1: Typical cervical vertebra, superior view.

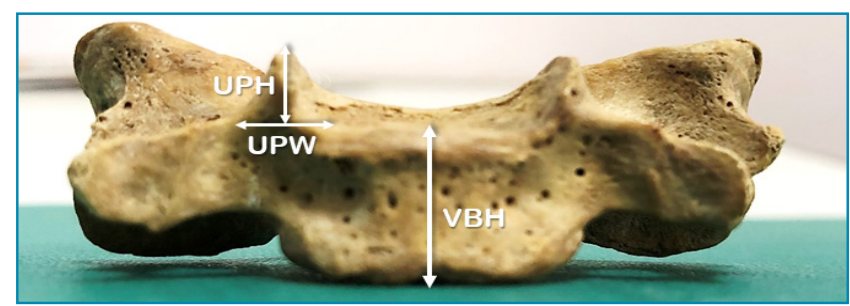

Fig. 2: Typical cervical vertebra, anterior view.

Maharajgunj Medical Campus from November 2019 to March of 2020. Damaged, diseased, and vertebra having erosions were excluded. The methods used to measure the dimensions of vertebrae in this study are similar to what has been used by various authors in different studies. ${ }^{12,13}$ For the measurement of uncinate process at $\mathrm{C} 7$, processes of both the sides had to be intact so as to achieve consistency while comparing the measurement of parallel sides in the same vertebra. Similarly, for measuring the Torg's ratio at $\mathrm{C} 7$, the diameter of anteroposterior vertebral body and vertebral

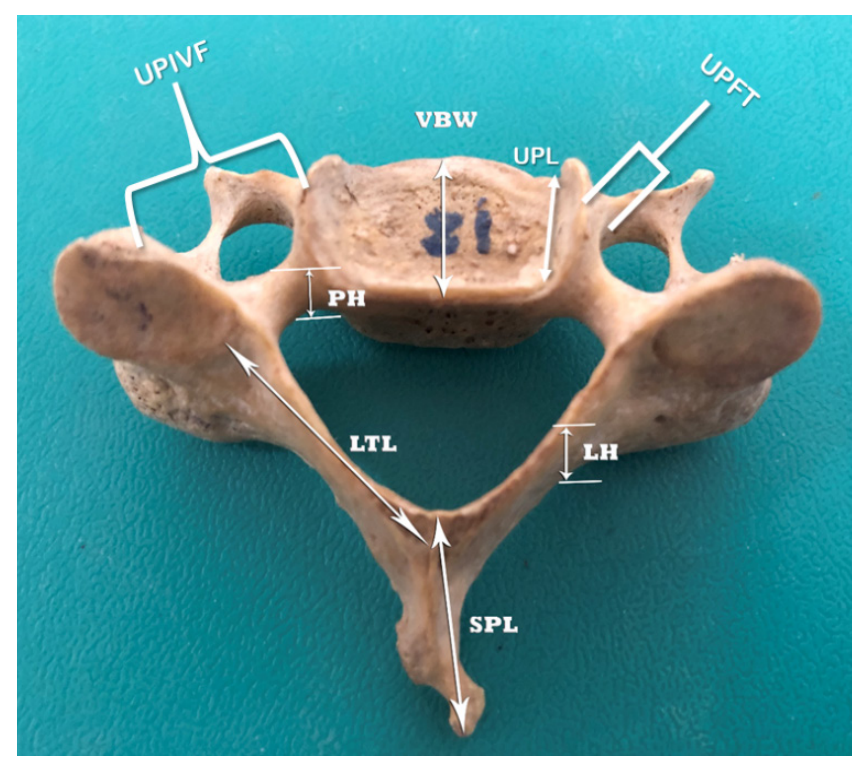

Fig. 3: Typical cervical vertebra, superior view. 
Table 1: Parameters measured in C3 to C7 Cervical Vertebra

\begin{tabular}{|c|c|c|}
\hline Measurement & Abbreviation & Description \\
\hline Vertebral body height & VBH & $\begin{array}{l}\text { Distance between superior and inferior margins of } \\
\text { the vertebral body at the midline anteriorly. }\end{array}$ \\
\hline $\begin{array}{l}\text { Vertebral body } \\
\text { anteroposterior width }\end{array}$ & VBW & $\begin{array}{l}\text { Distance between anterior and posterior surfaces of } \\
\text { the body at the medial line. }\end{array}$ \\
\hline Pedicle axis length & PAL & $\begin{array}{l}\text { Distance from the posterior cortex of the lateral mass } \\
\text { to the anterior wall of the vertebral body along the } \\
\text { pedicle axis. }\end{array}$ \\
\hline Pedicle width & PW & $\begin{array}{l}\text { The distance between medial and lateral margins of } \\
\text { pedicle. }\end{array}$ \\
\hline Pedicle height & $\mathrm{PH}$ & Rostrocaudal diameter of the pedicle. \\
\hline Lamina transverse length & LTL & $\begin{array}{l}\text { The distance between anterior margin of the spinous } \\
\text { process and lateral margin of the superior articular } \\
\text { process. }\end{array}$ \\
\hline Lamina height & $\mathrm{LH}$ & $\begin{array}{l}\text { The distance between superior and inferior margins } \\
\text { of the lamina. }\end{array}$ \\
\hline Uncinate process length & UPL & $\begin{array}{l}\text { The length between anterior and posterior parts of } \\
\text { the uncinate process. }\end{array}$ \\
\hline Uncinate process height & UPH & $\begin{array}{l}\text { Distance between the tip of the uncinate process and } \\
\text { the base of the uncinate process. }\end{array}$ \\
\hline Uncinate process width & UPW & $\begin{array}{l}\text { The distance between lateral and medial margins of } \\
\text { the uncinate process at the process base. }\end{array}$ \\
\hline Spinous process length & SPL & $\begin{array}{l}\text { The distance from anterior end of the base of the } \\
\text { spine to the longest tip of the bifurcated spine (tip of } \\
\text { the spine for C7). }\end{array}$ \\
\hline $\begin{array}{l}\text { Vertebral foramen anterior } \\
\text { posterior width }\end{array}$ & VFW & $\begin{array}{l}\text { The maximum anteroposterior length of foramen } \\
\text { vertebrae at the midline. }\end{array}$ \\
\hline $\begin{array}{l}\text { Vertebral foramen } \\
\text { transverse diameter }\end{array}$ & VFD & $\begin{array}{l}\text { Distance between two lateral limits of vertebral } \\
\text { foramen at the medial line. }\end{array}$ \\
\hline $\begin{array}{l}\text { Distance of apex of uncinate } \\
\text { process to intervertebral } \\
\text { foramen }\end{array}$ & UPIVF & $\begin{array}{l}\text { The distance of the apex of the uncinate process and } \\
\text { midpoint of medial edge of superior articulating } \\
\text { process. }\end{array}$ \\
\hline $\begin{array}{l}\text { Distance of apex of uncinate } \\
\text { process to foramen } \\
\text { transversarium }\end{array}$ & UPFT & $\begin{array}{l}\text { The distance of the apex of the uncinate process to } \\
\text { foramen transversarium. }\end{array}$ \\
\hline Torg’s ratio & TR & VFW divided by the VBW of the same vertebra. \\
\hline
\end{tabular}

foramen of the same vertebra was included. As comparison was made between the means of measurements of C3 to C6, same criteria were not followed in their case. All the measurements were done using Vernier Calipers of $0.1 \mathrm{~mm}$ caliber. The list of terminologies of all the measured parameters and their abbreviation and description is summarized in Table 1. The mean and standard deviation of various morphological parameters and comparison of the right and left sides are shown in Table 2 for C3 to C6 and C7 vertebra. Linear parameters were measured in millimeters $( \pm 1 \mathrm{~mm})$. The method of measurement is demonstrated in Fig. 1, 2 and 3.

Measurements were calculated for means and standard deviations. Values were compared using student's t-test. For statistical analysis we used a significance level of 5\% and Stata 16 software. 
Table 2: Measurements of various morphological parameters of C3-C6 and C7 Vertebrae

\begin{tabular}{|c|c|c|c|c|c|c|}
\hline \multirow[b]{2}{*}{ Measured Parameters } & \multicolumn{3}{|c|}{ C3-C6 (mm) } & \multicolumn{3}{|c|}{ C7 (mm) } \\
\hline & $\begin{array}{l}\text { Right (n), } \\
\text { Range }\end{array}$ & Left (n), Range & $\mathbf{P 1}$ & $\begin{array}{l}\text { Right (n), } \\
\text { Range }\end{array}$ & $\begin{array}{c}\text { Left (n), } \\
\text { Range }\end{array}$ & $\mathbf{P 2}$ \\
\hline Pedicle axis length & $\begin{array}{c}33.38 \pm 2.03 \\
(53), 29.0-36.0\end{array}$ & $\begin{array}{c}33.11 \pm 1.98(53) \\
29.0-35.0\end{array}$ & 0.49 & $\begin{array}{l}36.66 \pm 1.37 \\
(9), 30.0-38.5\end{array}$ & $\begin{array}{c}36.46 \pm 1.04 \\
(9), 29.0-37.0\end{array}$ & 0.73 \\
\hline Pedicle width & $\begin{array}{c}5.80 \pm 1.99 \\
(64), 4.0-6.0\end{array}$ & $\begin{array}{c}5.93 \pm 1.61(64) \\
4.0-7.0\end{array}$ & 0.69 & $\begin{array}{c}6.34 \pm 0.69 \\
(13), 4.5-8.0\end{array}$ & $\begin{array}{l}6.76 \pm 0.99 \\
(13), 4.0-8.0\end{array}$ & 0.22 \\
\hline Pedicle height & $\begin{array}{c}6.58 \pm 0.84 \\
(64), 5.0-8.5\end{array}$ & $\begin{array}{c}6.81 \pm 0.88(64) \\
5.0-9.0\end{array}$ & 0.13 & $\begin{array}{c}7.66 \pm 0.53 \\
(13), 5.0-9.0\end{array}$ & $\begin{array}{c}7.88 \pm 0.72 \\
(13), 5.5-8.5\end{array}$ & 0.38 \\
\hline Lamina transverse length & $\begin{array}{c}13.92 \pm 1.43 \\
(64), 10.0-15.0\end{array}$ & $\begin{array}{c}14.08 \pm 1.17(64) \\
11.0-16.5\end{array}$ & 0.50 & $\begin{array}{l}15.52 \pm 1.31 \\
(13), 11.5- \\
17.0\end{array}$ & $\begin{array}{c}14.86 \pm 1.06 \\
(13), 11.0- \\
16.0\end{array}$ & 0.17 \\
\hline Lamina height & $\begin{array}{c}10.07 \pm 0.92 \\
(64), 7.0-11.5\end{array}$ & $\begin{array}{c}10.51 \pm 1.03(64) \\
7.5-11.0\end{array}$ & $0.01^{*}$ & $\begin{array}{c}11.20 \pm 1.26 \\
(13), 9.5-13.0\end{array}$ & $\begin{array}{c}11.45 \pm 1.15 \\
(13), 9.0-13.5\end{array}$ & 0.60 \\
\hline Uncinate process length & $\begin{array}{c}10.33 \pm 1.05 \\
(37), 9.0-12.0\end{array}$ & $\begin{array}{c}10.58 \pm 1.35(34) \\
9.5-12.0\end{array}$ & 0.38 & $\begin{array}{c}9.68 \pm 1.82 \\
(8), 8.0-10.5\end{array}$ & $\begin{array}{c}9.47 \pm 1.36(8) \\
8.0-10.0\end{array}$ & 0.79 \\
\hline Uncinate process height & $\begin{array}{c}6.21 \pm 1.21 \\
(37), 3.0-7.5\end{array}$ & $\begin{array}{c}5.96 \pm 1.23(34) \\
3.0-7.5\end{array}$ & 0.39 & $\begin{array}{l}5.76 \pm 0.88 \\
(8), 4.0-6.5\end{array}$ & $\begin{array}{l}5.25 \pm 0.93 \\
(8), 4.0-6.5\end{array}$ & 0.28 \\
\hline Uncinate process width & $\begin{array}{c}3.54 \pm 0.75 \\
(37), 2.5-4.0\end{array}$ & $\begin{array}{c}3.25 \pm 0.87(34) \\
2.5-4.0\end{array}$ & 0.14 & $\begin{array}{l}4.76 \pm 0.80 \\
(8), 3.0-5.0\end{array}$ & $\begin{array}{l}4.81 \pm 0.61(8) \\
3.5-5.5\end{array}$ & 0.89 \\
\hline $\begin{array}{l}\text { Distance of apex of } \\
\text { uncinate process to } \\
\text { intervertebral foramen }\end{array}$ & $\begin{array}{c}6.67 \pm 1.61 \\
(37), 2.5-8.0\end{array}$ & $\begin{array}{c}6.71 \pm 1.72(34) \\
2.0-8.5\end{array}$ & 0.92 & $\begin{array}{c}6.20 \pm 1.30 \\
(8), 3.5-9.0\end{array}$ & $\begin{array}{c}6.80 \pm 1.42(8) \\
3.0-8.5\end{array}$ & 0.39 \\
\hline $\begin{array}{l}\text { Distance of apex of } \\
\text { uncinate process to } \\
\text { foramen transversarium }\end{array}$ & $\begin{array}{c}3.92 \pm 1.24 \\
(37), 2.0-5.5\end{array}$ & $\begin{array}{c}3.75 \pm 0.89(34) \\
2.5-5.0\end{array}$ & 0.51 & $\begin{array}{l}4.40 \pm 1.62 \\
(8), 3.0-5.5\end{array}$ & $\begin{array}{l}4.71 \pm 1.36(8) \\
2.5-6.5\end{array}$ & 0.68 \\
\hline Vertebral body height & \multicolumn{2}{|c|}{$12.43 \pm 1.39(53), 10.0-14.0$} & & \multicolumn{2}{|c|}{$13.90 \pm 1.12$ (9), $11.0-15.0$} & $0.004^{*}$ \\
\hline $\begin{array}{l}\text { Vertebral body } \\
\text { anteroposterior width }\end{array}$ & \multicolumn{2}{|c|}{$15.21 \pm 1.37$ (53), 10.0-18.5 } & & \multicolumn{2}{|c|}{$16.18 \pm 1.17(9), 14.0-19.5$} & $0.05^{*}$ \\
\hline Spinous process length & \multicolumn{2}{|c|}{$16.64 \pm 7.40(48), 8.0-31.0$} & & \multicolumn{2}{|c|}{$32.58 \pm 1.52$ (9), $31.0-35.0$} & $0.00^{*}$ \\
\hline $\begin{array}{l}\text { Vertebral foramen } \\
\text { anterior posterior width }\end{array}$ & \multicolumn{2}{|c|}{$14.43 \pm 1.44(64), 9.0-16.5$} & & \multicolumn{2}{|c|}{$15.68 \pm 1.11$ (13), $12.5-18.0$} & $0.00^{*}$ \\
\hline $\begin{array}{l}\text { Vertebral foramen } \\
\text { transverse diameter }\end{array}$ & \multicolumn{2}{|c|}{$22.39 \pm 1.72(64), 18.5-25.5$} & & \multicolumn{2}{|c|}{$21.96 \pm 0.91$ (13), 20.0-25.5 } & 0.36 \\
\hline Torg’s ratio & \multicolumn{2}{|c|}{$0.98 \pm 0.24$ (53), 0.97-1.02 } & & \multicolumn{2}{|c|}{$1.02 \pm 0.33$ (9), $1.00-1.05$} & 0.66 \\
\hline
\end{tabular}

Values within the parenthesis are the sample size. * Shows statistically significant values $(\mathrm{p}<0.05)$

\section{RESULTS}

The results of various measured parameters of C3 to C6 and C7 vertebra is shown is Table 2. In comparison to the right, the left $\mathrm{PH}$ of $\mathrm{C} 3$ to C6 was significantly larger. The Vertebral body height (VBH), Vertebral body width (VBW), Vertebral foramen width (VFW) and Spinous process length (SPL) of C7 were significantly larger than that of C3 to C6 vertebrae. All other comparisons made between $\mathrm{C} 3$ to $\mathrm{C} 6$ and $\mathrm{C} 7$ vertebrae were not significant statistically.

\section{DISCUSSION}

The anatomy of sub axial vertebra is important due to its clinical implications during surgical instrumentation of the area. The features of the vertebrae vary in dimension due to region, race, gender and genetic factors. ${ }^{5}$ The present study provides detailed morphometric information of dry sub axial cervical vertebrae of the local population.

The dimensions of vertebral body are useful 
during anterior cervical instrumentation like plate and screw fixation for reconstruction surgery. ${ }^{3,6}$ The mean and standard deviation of VBW of vertebral body in our study was similar to Mexican population $(14.68 \pm 2.63 \mathrm{~mm}$ to $17.42 \pm 1.33 \mathrm{~mm}$ ) at C3 to C7 levels and to the African population $(15.4 \pm 1.4 \mathrm{~mm})$ at $\mathrm{C} 3$ to C6 level. ${ }^{6,9}$ In contrast to this, our values were larger than the Indian population $(12.94 \pm 15.70$ $\mathrm{mm})$ but smaller than those reported of the Koreans $(16.0 \pm 1.0$ to $17.8 \pm 1.8))^{4,15,16}$ In the study by Nepal P. et al on Nepalese population the VBW was smaller $(14.57 \pm 1.24$ to $15.41 \pm 1.75 \mathrm{~mm})$ than the present study with larger values $(17.81 \pm 1.73 \mathrm{~mm})$ reported by Singh et al on the same population than ours. ${ }^{10-12}$

The morphometry of cervical pedicle is used in transpedicular screw fixation and to determine the size of the screw to be used during surgical treatment. Our measurements of PH and PW revealed a tendency which was comparable to the Chinese $(5.7 \pm 0.4$ to $7.2 \pm 0.7 \mathrm{~mm}$ and $4.4 \pm$ 1.0 to $5.8 \pm 0.6 \mathrm{~mm}$, respectively) and Brazilian $(6.8 \pm 0.86$ to $7.3 \pm 0.83$ and $5.1 \pm 0.78$ to $6.8 \pm 0.97$ $\mathrm{mm}$, respectively) study but larger than the Indian $(6.15 \pm 0.9$ to $6.75 \pm 1.09$ and $4.89 \pm 0.88$ to $6.19 \pm 1.01 \mathrm{~mm}$, respectively) report. ${ }^{4,7,8}$ While comparing our study, some results were differing, with larger $\mathrm{PH}$ and smaller $\mathrm{PW}$ $(7.08 \pm 4.48$ to $6.78 \pm 5.60 \mathrm{~mm}$ and $5.14 \pm 2.22$ to $4.78 \pm 1.01 \mathrm{~mm}$, respectively) with the Mexican study and comparable PW $(5.6 \pm 0.5$ to $6.9 \pm 0.9$ $\mathrm{mm})$ and larger $\mathrm{PH}(7.5 \pm 0.8$ to $7.9 \pm 0.9 \mathrm{~mm})$ with the Korean study. ${ }^{6,15}$ Our values of PAL were the largest among some of these studies. , $^{4,8}$

The dimensions of the lamina guide spine surgeons during laminoplasty procedures for multiple level cervical spine canal stenosis. Cervical laminectomy, laminoplasty and translaminar screw fixation are procedures involvedinsurgicaltreatment ofdecompression, spondylotic myelopathy and cervical spine instability ${ }^{6,14}$ In the present study, the $\mathrm{LH}$ and LTL correlated with the study of Indian (9.4511.97 and $13.31-14.86 \mathrm{~mm}$, respectively) and African $(10.0 \pm 1.2-10.4 \pm 1.3$ and $25.7 \pm 1.5$ to $24.6 \pm 1.8 \mathrm{~mm}$, respectively) population when we took the lowest and highest values from those studies..$^{4,9}$ Our values for LH were smaller when compared to that of the Mexican study (14.31 $1.50 \mathrm{~mm}){ }^{6}$ It is also important to note that there could also be variations of width and length of the lamina within the same study due to cervical enlargement of the cord. ${ }^{6}$

Uncinate process (UP) is defined as a bony protuberance that extends from posterior margin of vertebral body and participates in uncovertebral joint between the UP and vertebral body above. ${ }^{13}$ It extends from the third cervical vertebra down to the second thoracic vertebra, though mostly localized between third to seventh cervical vertebrae. These joints providestability tothecervicalspine. Procedures like uncinectomy and uncoforaminotomy are performed for conditions like cervical nerve irritation, vertebral artery narrowing and nerve root decompression. These procedures are dependent on the anatomic dimensions of the uncinate process. ${ }^{14}$ In comparing the findings of present study with the highest and lowest values of other studies, we found that the value of UPL was similar to Turkish $(9.3 \pm 1.66$ to $8.50 \pm 2.33 \mathrm{~mm})$ and Indian $(9.93 \pm 1.41$ to $12.50 \pm 2.86 \mathrm{~mm})$ study and smaller than the Korean $(11.0 \pm 0.6$ to $13.1 \pm 1.2 \mathrm{~mm})$ study. The UPH was similar to all the three populations compared. The UPW was smaller than that reported by the Turkish $(4.28 \pm 1.08$ to $5.38 \pm 0.88$ $\mathrm{mm})$ and Korean $(5.5 \pm 0.6$ to $6.3 \pm 0.9 \mathrm{~mm})$ study but larger than the Indian study $(2.60 \pm 0.5$ to $2.96 \pm 0.78 \mathrm{~mm}) .{ }^{13-15}$ Bozbuga et al. reported that the average width of the UP should be $4-6 \mathrm{~mm}$ for its uneventful removal, which is vital considering our values of UPW at C3 to C6 levels. ${ }^{17}$ The Values of UPFT are of significance during decompression of vertebral artery with anterior cervical approach. Taking the highest and lowest values of the measurements of UPIVF and UPFT of Turkish study, we found that our values were comparable with their UPIVF distances $(5.56 \pm 0.56$ to $6.56 \pm 1,14 \mathrm{~mm})$ but lesser with UPFT distances $(1.38 \pm 0.44$ to $3.16 \pm 0.93 \mathrm{~mm}){ }^{13}$

In comparison to African races the spinous process in the Whites tend to be short and bifid. ${ }^{18}$ The length of spinous process is crucial when considering screw placement for degenerative and traumatic lesions in it. Considering the highest and lowest values of spinous process length in the South Indian $(10.14 \pm 1.75$ to $22.78 \pm 2.03 \mathrm{~mm})$ and Mexican $(15.38 \pm 3.10$ to $29.12 \pm 5.86 \mathrm{~mm}$ ) study, our measurements were comparatively larger. ${ }^{6,19}$

In congenital and degenerative narrowing of cervical canal, the injury to the spinal cord, canal stenosis and myelopathy poses a significant risk factor. Therefore, morphometry of spinal canal also plays role in determining clinical outcome of factors causing canal narrowing. The transverse diameter of the cervical spinal canal is almost twice to that of the anteroposterior diameter (VFW). This also means that VFW is the limiting factor in an event of swelling or enlargement of structure there within. Also, in the diagnosis of cervical spine stenosis the VFW of the canal is more crucial than the transverse diameter..$^{20}$ Considering 
the lowest and highest values of VFW of C3 to C7 cervical spinal canal, we found that measurements of present study were similar to the Indian $(15.12 \pm 1.76$ to $16.93 \pm 2.45 \mathrm{~mm})$ study but larger than that of the Koreans $(12.8 \pm 1.4$ to $13.4 \pm 1.3 \mathrm{~mm}) .{ }^{16,20}$ Interestingly, the study by Singh et al reported a larger value of VFW in the Nepalese population. ${ }^{10}$

The Torg's ratio (TR) or canal- body ratio is a reliable value to determine the canal narrowing and advancing of clinical symptoms. ${ }^{20} \mathrm{~A}$ ratio of $>1.0$ indicates the absence of stenosis of the spinal canal, but a ratio of $<0.8$ implies the presence of stenosis. ${ }^{21}$ Two studies on Torg's ratio of Nepalese population were reviewed. The values of the present study was comparable to that of the work done by Rijal B et al $(0.99 \pm 0.09$ to $1.01 \pm 0.07 \mathrm{~mm}$ ) and larger to that reported by Singh et al $(0.97 \pm 0.13 \mathrm{~mm}) .^{10,12}$ In the cervical spine, the span of TR in the Koreans $(0.90 \pm 0.11$ to $1.05 \pm 0.10 \mathrm{~mm})$ and Indians $(0.95 \pm 0.06$ to $1.08 \pm 0.07 \mathrm{~mm}$ ) was similar. ${ }^{16,20}$ Including ours, the values of these studies indicated stenosis free cervical canal.

The cervicothoracic junction is an important anatomic area in relation to surgical context. C7 vertebra represents the transition of cervical lordosis to thoracic kyphosis. Presence of vital vascular and neural structure and comparatively narrow epidural space at this level makes surgical intervention very demanding. ${ }^{22}$ It is reported that $9 \%$ of all the cervical injuries occur at C7 level, and its morphology exhibits regional, ethnic and individual variations too. ${ }^{23}$ Among other techniques, anterior and posterior fixation techniques have been defined for the treatment of C7 lesion. The anteroroposterior diameter and height of the body of C7 is important for anterior fixation and bony structures like pedicle and lamina's length, height, width together with their angle to sagittal plane are vital for posterior fixation. ${ }^{23}$ Unlike our calculations on C7 vertebra (Table 2), the study by Keskin et al, reported that the anatomical features of lamina and pedicle confirms significance to side and gender difference. ${ }^{22}$ The morphological parameters of C7 in our study is larger in case of PAL and comparable for $\mathrm{PH}$, PW and LTL with other studies. The size of our LH is comparable to Indians (Right: $11.76 \pm 1.93$, Left: $12.19 \pm 2.25 \mathrm{~mm}$ ) but smaller to Koreans $(15.8 \pm 1.5,14.8 \pm 1.6 \mathrm{~mm})$ and Mexicans (14.31 \pm $1.50 \mathrm{~mm})^{6,14,15}$ Overall, our findings reflect optimistic values for surgical intervention of C7 in our local populace.

This study documents the morphological data of sub axial vertebrae. Paired values were evaluated and except the height of left lamina of C3 to C6 vertebrae, none of them showed significant side difference. Similarly, assessment of the mean values of VBH, VBA, PW, SPL, VFA and PW of C3-C6 and C7 vertebrae found higher values of C7 which were statistically significant. When comparing our findings with the data of the Indian, Turkish, Chinese, Korean, Brazilian and Mexican population in literature, the results were mixed. Regardless of this, it is notable to mention that most of our observations either compared to (lamina, UP, AP-diameter of spinal canal and Torg's ratio) or were larger (Pedicle and SP) than the Indian study with PAL being largest among compared studies. In relation to C7 vertebra, our measurements were similar to other studies except for the dimension of lamina height which was significantly smaller in our case but was comparable to that of the study in Indian subjects. The comparison of values of uncinate process length and width were highly variable but the values of uncinate process height stayed similar. Overall, in case of the observed differences, it could be speculated to be due to genetic and racial factors, samples (living persons, cadavers, dry bones etc.), sample size, instrument of measurement (Vernier Calipers, CT, and X-rays etc.), statistical tools used or criteria of sample selection. The information of this study may be used as a reference database for our local setting and could be of value in preoperative planning. Present data would equally be useful in designing implants and identifying osteological remains. Finally, since the relationship with reference to the level of each vertebra (C3 to C6) could not be established due to samples not being tagged nor having a data record for identification, a radiological study is recommended at a segmental level for a detailed exploration of the topic under discussion.

\section{ACKNOWLEDGEMENT}

The authors express their gratitude to all other members in the Department of Anatomy of Birat Medical College and Tribhuvan University Teaching Hospital for their support and contribution.

\section{REFERENCES}

1. Tubbs RS, Rompala OJ, Verma K et al. Analysis of the uncinate processes of the cervical spine: an anatomical study. J Neurosurg Spine 2012; 16: 402-7. 
2. Karaikovic EE, Daubs MD, Madsen RW, Gaines RW, Jr. Morphologic characteristics of human cervical pedicles. Spine (Phila Pa 1976) 1997; 22: 493-500.

3. Abuzayed B, Tutunculer B, Kucukyuruk B, Tuzgen $\mathrm{S}$. Anatomic basis of anterior and posterior instrumentation of the spine: morphometric study. Surg Radiol Anat 2010; 32: 75-85.

4. Banerjee PS, Roychoudhury AK, Karmakar SK. Morphometric analysis of the cervical spine of Indian population by using computerized tomography. J Med Allied Sci 2012; 2: 66-76.

5. Chazono M, Tanaka T, Kumagae Y, Sai T, Marumo $\mathrm{K}$. Ethnic differences in pedicle and bony spinal canal dimensions calculated from computed tomography of the cervical spine: a review of the English-language literature. Eur Spine J 2012; 21: $1451-8$

6. Bazaldúa Cruz JJ, González Larios A, Gómez Sánchez A et al. Morphometric study of cervical vertebrae C3-C7 in a population from Northeastern Mexico. Int'l J Morphol 2011; 29: 325-30.

7. Ruofu Z, Huilin Y, Xiaoyun H et al. CT evaluation of cervical pedicle in a Chinese population for surgical application of transpedicular screw placement. Surg Radiol Anat 2008; 30: 389-96.

8. Herrero CF, Luis do Nascimento A, Maranho DA et al. Cervical pedicle morphometry in a Latin American population: A Brazilian study. Medicine (Baltimore) 2016; 95(25): e3947.

9. Ndulu Ishigita M, Joseph O, Ian M et al. Cervical vertebrae at the Galloway osteological collection: A morhphometric study. Acad Anatomica Int'l 2017; 4(1): 45-51.

10. Singh S, \& Balakrishnan, M. Morphometric study of cervical spine vertebrae in eastern region Nepalese population. Health Renaissance 2014; 11: 224-8.

11. Nepal PR, Rijal S, Shrestha J, Devkota U. Anthropometric study of cervical spine in sdult Nepalese. J Spinal Surg 2017; 4: 55-9.

12. Rijal B, Pokharel RK, Paudel S, Shah LL. Torg's ratio in normal adult nepalese population. J Soc Surg Nep 2015; 18: 5-19.
13. Tunali NKA-NEA-S. Morphometric analysis of the uncinate processes of the cervical vertebrae. Folia Morphol (Warsz) 2017; 76: 440-5-5.

14. Raveendranath V, Kavitha T, Umamageswari A. Morphometry of the uncinate Process, vertebral Body, and lamina of the C3-7 vertebrae relevant to cervical spine surgery. Neurospine 2019; 16: 748-55.

15. Lee TH, Kim SJ, Chung IH. Morphometrical study of uncinate processes and vertebral body of cervical spine. J Korean Neurosurg Soc 2012; 51: 247-52.

16. Kathole MA, Joshi RA, Herekar NG, Jadhav SS. Dimensions of spinal canal and vertebra and their relevance in clinical practice. Int'l J Recent Trends Sci Technol 2012; 3: 54-8.

17. Bozbv a M, Oztürk A, Ari Z, Bayraktar B, Sahinoglu K, Gürel Ii. Surgical anatomic evaluation of cervical uncinate process for ventral and ventrolateral subaxial decompression. Okajimas Folia Anatomica Japonica 1999; 76: 193-6.

18. Duray SM, Morter HB, Smith FJ. Morphological variation in cervical spinous processes: potential applications in the forensic identification of race from the skeleton. J Forensic Sci 1999; 44: 937-44.

19. Gajendran P, Xavier Chandra P, Ganapathy A, Tirugnanam S. Morphometric study of cervical vertebrae C3-C7 in South Indian population -A clinico-anatomical approach. Italian J Anat Embryol 2017; 122: 49-57.

20. Lee HM, Kim NH, Kim HJ, Chung IH. Mid-sagittal canal diameter and vertebral body/canal ratio of the cervical spine in Koreans. Yonsei Med J 1994; 35: 446-52.

21. Torg JS, Pavlov H, Genuario SE et al. Neurapraxia of the cervical spinal cord with transient quadriplegia. J Bone Joint Surg Am 1986; 68: 1354-70.

22. Keskin F, Erdi F, Nayman A, Babaoglu O, Erdal $\mathrm{K}$, Ozer AF. Radiological anatomy of the C7 vertebra: Clinical implications in spine surgery. J Craniovertebr Junction Spine 2015; 6: 30-5.

23. Tse MSH, Chan $\mathrm{CH}$, Wong $\mathrm{KK}$, Wong WC. Quantitative anatomy of C7 vertebra in Southern Chinese for insertion of lateral mass screws and pedicle screws. Asian Spine J 2016; 10: 705-10. 